\title{
PARTISIPASI KELOMPOK TANI TERHADAP DINAMIKA KELOMPOK TANI DI DESA ONGKAW DUA KECAMATAN SINONSAYANG KABUPATEN MINAHASA SELATAN
}

\author{
Asri Indri Roring \\ Celcius Talumingan \\ Agnes E. Loho
}

\begin{abstract}
This study aims to determine the participation of farmer groups against the dynamics of farmer groups in the Village Ongkaw Dua Sinonsayang District South Minahasa District. This research was carried out in Ongkaw Dua Village, Sinonsayang District, South Minahasa District for 3 months starting from February 2017 until April 2017 starting from preparation, taking data to preparing research report. Data collection methods in this study using primary data and secondary data. Primary data were obtained directly from the source through surveys and interviews using questionnaires to the Four Farmers Group of the Ark, Sinar Baru, Bersehati, Blessing each five group members consisting of chairman, secretary, treasurer, and two members of the farmer group, while secondary data was obtained from institutions related to the research of the village government Ongkaw Dua Based on the results of descriptive analysis it can be seen that the number of farmer group participation index to the dynamics of farmers group is very good with the score obtained is 3600 .
\end{abstract}

Keywords: Farmer Group, Participation, Group Dynamics, Sub-district Sinonsayang

\begin{abstract}
ABSTRAK
Penelitian ini bertujuan untuk mengetahui partisipasi kelompok tani terhadap dinamika kelompok tani di Desa Ongkaw Dua Kecamatan Sinonsayang Kabupaten Minahasa Selatan. Penelitian ini dilaksanakan di Desa Ongkaw Dua Kecamatan Sinonsayang Kabupaten Minahasa Selatan selama 3 bulan mulai dari bulan Februari 2017 sampai bulan April 2017 mulai dari persiapan, pengambilan data sampai pada penyusunan laporan hasil penelitian. Data yang digunakan dalam penelitian ini adalah data primer dan data sekunder. Data primer diperoleh langsung dari sumbernya dengan menggunakan daftar pertanyaan kepada Empat Kelompok Tani yaitu Bahtera, Sinar Baru, Bersehati, Berkat Masing-Masing Kelompok Tani diambil lima sampel yang terdiri ketua, sekertaris, bendahara, dang dua anggota kelompok tani, Data sekunder diperoleh dari lembaga yang terkait dengan penelitian yaitu pemerintah Desa Ongkaw Dua Data dianalisis dengan menggunakan analisis. Hasil penelitian menunjukkan bahwa partisipasi kelompok tani terhadap dinamika kelompok tani tergolong sangat baik dengan skor yang didapat yaitu 3600 .
\end{abstract}

Kata kunci: kelompok tani, partisipasi, dinamika kelompok, Kecamatan Sinonsayang

\section{PENDAHULUAN}

\section{Latar Belakang}

Salah satu Kebijakan yang ditempuh pemerintah untuk mewujudkan tujuan pembangunan nasional ialah peningkatan kehidupan ekonomi yang dilakukan melalui pembangunan pertanian. Hal ini sesuai karena negara Indonesia adalah negara agraris dan sebagian besar mata pencaharian penduduknya adalah bercocok tanam (Hernanto, 2001).

Sektor pertanian menjadi sektor yang penting di pedesaan dalam meningkatkan tingkat ekonomi, teknologi dan sosial di 
pedesaan khusunya bagi petani. Minimnya partisipasi petani di pedesaan terhadap sektor pertanian disebabkan oleh berbagai faktor seperti pendidikan, umur, dan pengalaman bertani. Salah satu usaha untuk mempertahankan dan mengembangkan usaha pertanian adalah adanya penyuluhan agar tingkat partisipasi petani semakin meningkat.

Partisipasi anggota atau partisipasi kelompok tani merupakan keikutsertaan dari anggota atau petani baik secara individu maupun secara kelompok dengan penuh kesadaran dan tanggung jawab, partisipasi anggota merupakan factor yang sangat penting untuk Tujuan dinamika kelompok demi tercapainya tujuan kelompok yang ditentukan dengan adanya tindakan yang dilakukan oleh anggota kelompok. Adanya dinamika kelompok tersebut, mampu memberi peluang yang sebesar-besarnya kepada setiap anggota kelompok untuk bekerjasama dan berpartisipasi dalam kegiatan kelompok, sehingga melalui kerjasama dan partisipasi anggota inilah tujuan program dalam pembangunan, khususnya pembangunan pertanian dapat berhasil dan berjalan dengan baik. Dinamika kelompok diharapkan dapat menjadikan kelompok yang bersangkutan mempunyai kelebihan untuk menjalankan setiap aktivitas bagi kepentingan kelompok. Partisipasi anggota terhadap dinamika kelompok meliputi bentuk- bentuk partisipasi, fungsi dinamika kelompok dan tujuan dinamika kelompok.

Kelompok tani terus berkembang di Minahasa Selatan seperti yang ada di Kecamatan amurang barat seperti desa kapitu, desa tewasen dan lain sebaginya. di Minahasa Selatan, salah satunya yang saat ini sudah dikenal di Sulawesi Utara yang memiliki kelompok tani, bahkan di Indonesia. Dari sejumlah desa di atas, maka Ongkaw Dua yang di jadikan lokasi dalam penelitian ini. Desa Ongkaw Dua juga memiliki berbabagai tingkatan kelompok tani mulai dari tingkat pemula, sampai lanjut yang telah ada sampai saat ini.
Desa Ongkaw Dua yang terletak di Kecamatan Sinonsayang Kabupaten Minahasa Selatan ini memiliki luas wilayah sekitar $\pm 1500 \mathrm{~m} 2$ dengan jumlah penduduk 1958 jiwa yang terdiri dari 986 laki - laki jiwa dan 972 perempuan jiwa. Adapun jumlah kelompok tani yang ada di Desa Ongkaw Dua terdapat 4 kelompok tani yaitu kelompok tani Sinar Baru terbentuk pada tahun 2006, kelompok tani Bahtera terbentuk pada tahun 2006, Kelompok tani Bersehati terbentuk pada tahun 2006 dan kelompok tani Berkat terbentuk pada tahun 2009 .

\section{Perumusan Masalah}

Berdasarkan latar belakang yang telah diuraikan maka rumusan masalah dalam penelitian ini adalah bagaimana Partisipasi Kelompok Tani Terhadap Dinamika Kelompok Tani di Desa Ongkaw Dua Kecamatan Sinonsayang Kabupaten Minahasa Selatan?

\section{Tujuan Penelitian}

Dari rumusan masalah diatas, yang menjadi tujuan dari penulisan makalah ini yaitu untuk mengetahui partisipasi kelompok tani terhadap dinamika kelompok tani di desa Ongkaw Dua Kecamatan Sinonsayang Kabupaten Minahasa Selatan.

\section{Manfaat Penelitian}

Penelitian ini diharapkan dapat memberikan kontribusi kepada para petani terlebih khusus anggota Kelompok Tani Bahtera, Sinar Baru, Bersehati, Dan Berkat, untuk mengetahui partisipasi terhadap dinamika kelompok yang terdapat dalam kelompok tani di Desa Ongkaw Dua dan menjadi bahan masukan bagi kelompok tani lainnya.

\section{METODOLOGI PENELITIAN}

\section{Lokasi dan Waktu Penelitian}

Lokasi penelitian ini dilakukan di Desa Ongkaw Dua Kecamatan Sinonsayang Kabupaten Minahasa Selatan dan waktu penlitian dilakukan selama 3 bulan dari bulan Februari sampai April 2017, mulai dari persiapan sampai selesai. 


\section{Metode Pengumpulan Data}

Data yang digunakan dalam penelitian ini menggunakan data primer dan data sekunder. Data primer diperoleh dari wawancara langsung dari sumbernya melalui teknik survey dengan wawancara langsung, sedangkan data sekunder diperoleh dari lembaga yang terkait dengan masalah penilitian yaitu pemerintah Desa Ongkaw Dua. Responden adalah Ketua, Sekertaris, Bendahara dan Dua Anggota.

\section{Konsepsi Pengukuran Variabel}

Indikator penelitian yang dikaji dalam penelitian ini adalah :

1. Karakteristik Kelompok Tani
1) Nama Kelompok Tani
2) Tahun Terbentuk
3) Keanggotaan
4) Lahan yang digunakan
5) Jenis Usaha

2. Karakteristik Responden
1) Umur anggota Kelompok Tani (dalam tahun)
2) Tingkat Pendidikan formal
3) Pekerjaan

3. Partisipasi

a. Partisipasi Bah Pikiran, yaitu menymbangkan ide/gagasan, pendapat, saran, kritik dan pengalaman keberlangsungan kegiatan bermutu.

1. Adanya ide atau gagasan

2. Pendapat/Saran

3. Pengalaman

b. Partisipasi tenaga, dalam berbagai kegiatan untuk perbaikan atau pembangunan, pertolongan bagi orang lain, partisipasi spontan atas dasar sukarela.

1. Pemberian diri

2. Kesiapan dari anggota

3. Membantu secara sukarela

c. Partisipasi harta benda, menyumbangkan materi berupa uang, barang dan penyediaan sarana dan fasilitas untuk kepentingan program.

1. Memberikan bantuan berupa materi
2. Memberikan bantuan berupa barang dan penyediaan sarana/fasilitas

3. Memberikan atau meminjamkan lahan pertanian

d. Partisipasi keterampilan, yaitu berupa pemberian bantuan skill yang dimiliki untuk perkembangan program.

1. Berbagi ilmu

2. Membantu kelompok tani dengan berinovasi

3. Kerjasama anggota kelompok

e. Partisipasi sosial, yaitu keterlibatan dalam kegiatan-kegitan sosial demi kepentingan bersama.

1. Pemberian diri

2. Keterlibatan anggota membantu pemerinta desa

3. Peran aktif anggota dalam kegiatan.

4. Dinamika Kelompok

Fungsi Dinamika Kelompok:

a. Kerja sama

1. Kerja sama dalam anggota kelompok

2. Kekompakkan sesama anggota

3. Bekerja sama dengan pemerintah

b. Kemudahan Pekerjaan

1. Kemudahan anggota dalam kelompok

2. Kebersamaan dalam kelompok

3. Memijamkan peralatan pertanian dalam kelompok.

c. Membutuhkan pemecahan masalah dan pekerjaan yang terlalu besar.

1. Mengatasi pekerjaan dengan cepat dan tepat waktu

2. Mengurangi beban pekerjaan

3. Mengontrol pekerjaan yang dikerjakan anggota.

Tujan Dinamika Kelompok:

a. Meningkatkan proses interaksi antar anggota kelompok sehingga menyebabkan terjalinnya hubungan psikologis yang nyata diantara angggota kelompok, rasa memiliki kelompok, rasa saling tergantung diantara anggota kelompok. 
1. Menjalin hubungan yang baik dalam kelompok tani

2. Rasa memiliki sesame anggota

3. Saling ketergantunagan

b. Meningkatkan produktivitas kelompok melalui peningkatan pengetahuan, sikap dan keterampilan anggota kelompok.

1. Peningkatan pengetahuan

2. Tanggung jawab dari anggota

3. Memberikan keterampilan.

c. Mengembangkan kelompok kearah yang lebih baik, maju dan kompak.

1. Mengembangkan kelompok kearah yang lebih baik, maju dan kompak

2. Usaha setiap kelompok taniuntu kemajuan kelompok

3. Kekompakkan dari anggota kelompok

d. Meningkatkan kesejahteraan hidup anggota kelompok.

1. Mengontrol setiap kegiatan anggota

2. Bantan digunakan sesuai dengan program usaha tani

3. Meningkatkan kegiatan usaha tani.

\section{Metode Analisis Data}

Metode analisis data yang digunakan dalam penelitian ini adalah analisi deskriptif, Untuk mendeskripsikan partisipasi anggota terhadap dinamika kelompok tani di Desa Ongkaw 2 (dua) Kecamatan Sinonsayang Kabupaten Minahasa Selatan yaitu dengan menggunakan skala likert.

Variabel penelitian digunakan maka dilakukan pengukuran dengan cara menguraikan indikator-indikator variabel dalam bentuk item-item pertanyaan yang disusun dalam bentuk kuesioner dengan bobot nilai (skor) jawaban 1-5, untuk membantu analisa data digunakan skor, Sangat Setujui (skor 5), Setuju (skor 4), Netral (skor 3), Tidak Setuju (skor 2) Sangat Tidak Setuju (skor 1).

Cara pengukuran skor keseluruhan untuk mengetahui Partisipasi Anggota
Terhadap Dinamika Kelompok Tani Di Desa Ongkaw dua (2).

Jumlah skor seluruh krietria = Capaian jumlah skor X Jumlah responden instrument pertanyaan.

Skor $5=5 \times 20 \times 36=3600$

Skor $4=4 \times 20 \times 36=2880$

Skor $3=3 \times 20 \times 36=2160$

Skor $2=2 \times 20 \times 36=1440$

Skor $1=1 \times 52 \times 36=720$

Jumlah skor ideal untuk keseluruhan pertanyaan $=3600$

Jumlah skor terendah $=720$

Dengan interpretasi nilai:

$$
\frac{720}{3600}=20 \%
$$

$\frac{1440}{3600}=40 \%$

$\frac{2160}{3600}=60 \%$

$\frac{2880}{3600}=800 \%$

$\frac{3600}{3600}=100 \%$

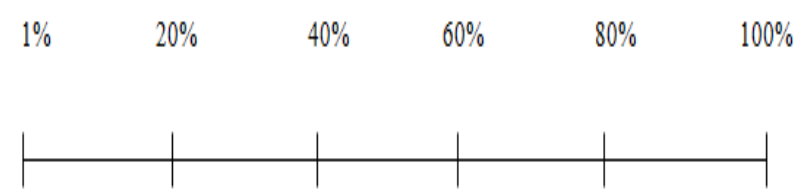

Sangat rendah Rendah Sedang Tinggi Sangat Tinggi

Keterangan kriteria interpretasi skor partisipasi :

Angka 1\% - 20\% = Sangat Rendah

Angka 21\% - 40\% = Rendah

Angka 41\% - 60\% = Sedang

Angka 61\% - 80\% = Tinggi

Angka 81\% - 100\% = Sangat Tinggi .

Mengukur Tingkat Partisipasi= $\frac{\text { Jumlah skor hasil pengumpulan data }}{\text { Jumlah skor ideal (Tertinggi) }} \boldsymbol{x} \mathbf{1 0 0 \%}$ 


\section{HASIL DAN PEMBAHASAN}

\section{Deskripsi Wilayah Penelitian}

\section{Sejarah Desa Ongkaw Dua}

Desa Ongkaw Dua merupakan salah satu desa yang berada di kecamatan Sinonsayang , Kabupaten Minahasa Selatan, Provinsi Sulawesi Utara, Indonesia. Desa ini merupakan ibu kota Kecamatan Sinonsayang . Desa Ongkaw Dua adalah hasil pemekaran dari Desa Ongkaw Raya yang sekarang terbagi menjadi tiga desa, yaitu:

1. Desa Ongkaw Satu

2. Desa Ongkaw Dua

3. Desa Ongkaw Tiga

Desa Ongkaw Dua terletak diantara desa Ongkaw Satu dan Desa Ongkaw Tiga, yang diapit dengan sungai besar dikedua ujung desa. Awal mula terjadinya Desa Ongkaw berawal dari datangnya sekelompok orang yang bersuku Tontemboan Minahasa. Mereka datang membuka lahan kebun baru. Sebenarnya nama dari desa "Ongkaw" sendiri berasal dari Bolaang Mongondow yang berarti: "Batu Melimpah" atau "Banyak Batu". Jika ditelusuri keadaan sungai dan tepi lautnya hampir $100 \%$ dipenuhi dengan batu. Terbukti juga dengan ditemukan salah satu situs Budaya Minahasa berupa "Batu Lisung" dipuncak Gunung Sinonsayang .

\section{Letak Geografis}

Desa Ongkaw Dua adalah sebuah desa yang terletak di Kecamatan Sinonsayang , Kabupaten Minahasa Selatan, Provinsi Sulawesi Utara, yang terdiri dari 10 jaga atau dusun dengan batas Wilayah:

1. Sebelah Utara : Desa Boyong Pante

2. Sebelah Timur : Desa Tiniawangko dan Desa Tondey

3. Sebelah Selatan : Desa Ongkaw Satu

4. Sebelah Barat : Laut Sulawesi

Desa Ongkaw Dua memiliki luas wilayah sekitar $\pm 1500 \mathrm{~m}^{2}$, dilihat dari topografi dan kotur tanah Desa Ongkaw Dua secara umum berupa datar rendah atau perbukitan yang berada pada ketinggian antara $5 \mathrm{~m}$ sampai $500 \mathrm{~m}$ dari permukaan laut.

\section{Keadaan Penduduk}

Jumlah penduduk yang ada di Desa Ongkaw Dua sebanyak 1958 jiwa, dengan jumlah laki - laki sebanyak 986 jiwa dan perempuan sebanyak 972 jiwa .

\section{Deskripsi Kelompok Tani}

Kelompok tani di Desa Ongkaw II yang menjadi Responden penelitian memiliki sejarah singkat. Dan dapat dlihat pada tabel di bawah.

Tabel 1 Karakteristik Kelompok Tani

\begin{tabular}{clcc}
\hline No & $\begin{array}{c}\text { Kelompok } \\
\text { Tani }\end{array}$ & $\begin{array}{c}\text { Tahun } \\
\text { Terbentuk }\end{array}$ & Kelas \\
\hline 1 & Berkat & 2009 & Lanjut \\
2 & Sinar Baru & 2006 & Pemula \\
3 & Bersehati & 2006 & Lanjut \\
4 & Bahtera & 2006 & Pemula \\
\hline
\end{tabular}

Terbentuknya kelompok tani atas dasar keputusan bersama dan menjadi motivasi karena sebagian besar anggota atau petani pada waktu itu masih kekurangan ilmu bercocoktanam, sehingga membentuk kelompok tani untuk merangkul para petani agar bias bercocok tanam dan saling berbagi ilmu tentang kegiatan pertanian dan cara menggunakan teknologi pertanian agar bisa meningkatkan hasil pertanian dan mampu mensejahterakan anggota kelompok tani.

\section{Karakteristik Responden}

Kemampuan bekerja atau melakukan aktivitas secara fisik bahkan cara berfikir seseorang sangat dipengaruhi faktor umur. Demikian juga dengan para anggota kelompok tani dalam melakukan pekerjaannya, anggota yang memiliki umur muda tentunya memiliki kondisi fisik yang lebih kuat serta memiliki daya berfikir yang lebih kreatif dibandingkan yang lebih tua. Dari data primer yang diperoleh, anggota kelompok tani berusuia 35 - 60 tahun.

Peranan pendidikan formal sangat penting dalam usaha peningkatan kualitas seseorang karena berguna dalam pembangunan pribadi serta peningkatan intelektual dan wawasan seseorang. Berdasarkan hasil penelitian, tingkat pendidikan responden bervariasi mulai dari tingkat Sekolah Dasar (SD), Sekolah Lanjutan Tingkat Pertama (SLTP) sebanyak 8 responden, Sekolah Lanjutan Tingkat Atas (SLTA) 
sebanyak 11 responden sampai Perguruan Tinggi (SARJANA) sebanyak 1 responden.

Pekerjaan dari responden yaitu semuanya adalah petani dan IRT, Petani berjumlah 11 orang dan IRT berjumlah 9 orang.

\section{Partisipasi Kelompok Tani Terhadap Dinamika Kelompok Tani Di Desa Ongkaw Dua}

Ada beberapa Bentuk - bentuk partisipasi dalam penelitian ini dengan kelas pemula dan kelas lanjut yaitu partisipasi buah pikiran, partisipasi tenaga, partisipasi harta benda, partisipasi keterampilan, partisipasi sosial dengan total skor dan interpretasi yang berbeda dan dapat dilihat pada Tabel di bawah.

Tabel 2 Intepretasi Bentuk - Bentuk Partisipasi Kelompok Tani di Desa Ongkaw Dua

\begin{tabular}{lcc}
\hline $\begin{array}{c}\text { Bentuk - Bentuk } \\
\text { Partisipasi }\end{array}$ & Kelas Pemula & Kelas Lanjut \\
\hline Buah fikiran & 132 & 116 \\
Tenaga & 122 & 121 \\
Harta Benda & 116 & 106 \\
Keterampilan & 121 & 120 \\
Sosial & 124 & 122 \\
\hline Jumlah & 615 & 585 \\
\hline
\end{tabular}

Dapat dilihat tingkat partisiapasi kelas pemula dan kelas lanjut menunjukkan bahwa kelas pemula lebih tinggi total skornya yaitu 615 dan mendapatkan interpretasi nilai yang sangat tinggi dari pada kelas lanjut yang hanya mendapatkan total skor 585 dan mendapatkan interpretasi nilai yang sedang. Ini menunjukkan bahwa kelas pemula lebih berpartisipasi dibandingkan dengan kelas lanjut.

\section{Fungsi Dinamika Kelompok}

Terdapat tiga fungsi dinamika kelompok yang menjadi konsep variabel yaitu membentuk kerjasama yang saling menguntungkan, memudahkan pekerjaan dan Mengatasi Pekerjaan Yang Membutuhkan Pemecahan Masalah. Dan terbagi dalam dua kelas atau tingkatan yaitu dapat dilihat pada Tabel dibawah ini.
Tabel 3 Intepretasi Fungsi Dinamika Kelompok Tani di Desa Ongkaw Dua

\begin{tabular}{lll}
\hline Fungsi Dinamika Kelompok & $\begin{array}{l}\text { Kelas } \\
\text { Pemula }\end{array}$ & $\begin{array}{l}\text { Kelas } \\
\text { Lanjut }\end{array}$ \\
\hline $\begin{array}{l}\text { Kerja Sama } \\
\text { Kemudahan Pekerjaan }\end{array}$ & 125 & 129 \\
$\begin{array}{l}\text { Pemecahan Masalah dan } \\
\text { Pekerjaan Yang Terlalu } \\
\text { Besar }\end{array}$ & 120 & 121 \\
\hline Jumlah & 371 & 124 \\
\hline
\end{tabular}

Dapat dilihat tingkat partisipasi dalam fungsi dinamika kelompok kelas pemula dan kelas lanjut dari Tabel 9 dan 10 menunjukkan bahwa kelas lanjut lebih tinggi total skornya yaitu 375 dari pada kelas pemula yang mendapatkan total skor yaitu 371, dan keduanya mendapatkan interpretasi nilai tergolong sangat tinggi.

\section{Tujuan Dinamika Kelompok}

Terdapat empat tujuan dinamika yang menjadi konsep variabel yaitu Meningkatkan Proses Interaksi Antara sesama anggota kelompok, meningkatkan produktivitas kelompok, mengembangkan kelompok kearah yang lebih baik, meningkatkan kesejahteraan anggota kelompok. Dan terbagi dalam dua kelas atau tingkatan yaitu kelas pemula dan kelas lanjut dilihat pada Tabel dibawah ini.

Tabel 4 Intepretasi Tujuan Dinamika Kelompok Tani di Desa Ongkaw Dua

\begin{tabular}{lcc}
\hline Tujuan Dinamika Kelompok & $\begin{array}{c}\text { Kelas } \\
\text { Pemula }\end{array}$ & $\begin{array}{c}\text { Kelas } \\
\text { Lanjut }\end{array}$ \\
\hline $\begin{array}{l}\text { Meningkatkan Proses } \\
\text { Interaksi }\end{array}$ & 122 & 121 \\
$\begin{array}{l}\text { Meningkatkan Produktivitas } \\
\text { Kelompok }\end{array}$ & 120 & 122 \\
$\begin{array}{l}\text { Mengembangkan Kelompok } \\
\text { Meningkatkan }\end{array}$ & 139 & 128 \\
Kesejahteraan & 146 & 145 \\
Hidup Anggota & & \\
\hline Jumlah & 527 & 516 \\
\hline
\end{tabular}

Dapat dilihat dari hasil yang diperoleh kelas pemula dan kelas lanjut tingkat partisipasi dalam tujuan dinamika kelompok kelas pemula yang mendapatkan skor lebih diatas yaitu 527 dari pada kelas lanjut yaitu 516, namun kelas pemula dan kelas lanjut mendapatkan interpretasi nilai yang sama tergolong sangat tinggi, itu berarti partisipasi kelompok dalam tujuan dinamika kelompok baik. 


\begin{tabular}{llrr} 
Hubungan Partisipasi & dan & \multicolumn{2}{c}{ Dinamika } \\
Kelompok Tani Desa & Ongkaw Dua \\
Kecamatan Sinonsayang & & Kabupaten \\
Minahasa Selatan & &
\end{tabular}

Hasil keseluruhan total skor yang diperoleh dari 15 indikator pertanyaan bentuk bentuk partisipasi, 9 indikator pertanyaan fungsi dinamika, 12 indikator pertanyaan tujuan dinamika dapat dilihat pada Tabel di bawah.

Tabel 5 Hubungan Partisipasi dan Dinamika Kelompok Tani Desa Ongkaw

\begin{tabular}{lccc}
\hline & $\begin{array}{c}\text { Fungsi } \\
\text { Dinamika } \\
\text { Kelompok }\end{array}$ & $\begin{array}{c}\text { Tujuan } \\
\text { Dinamika } \\
\text { Kelompok }\end{array}$ & Total \\
\hline $\begin{array}{l}\text { Partisipasi } \\
\text { Pemula } \\
(615)\end{array}$ & 371 & 527 & 1513 \\
$\begin{array}{l}\text { Partisipasi } \\
\text { Lanjut } \\
\text { (585) }\end{array}$ & 375 & 516 & 1476 \\
\hline Jumlah & & & \\
\hline
\end{tabular}

Hasil penelitian menunjukkan bahwa hubungan kelompok tani kelas lanjut dan pemula dalam partisipasi dan fungsi dinamika kelompok mempunyai hubungan terbalik karena tingkat partisipasi kelas pemula lebih tinggi total skor 615 dibandingkan kelas lanjut yang hanya 585, terbalik dengan tingkat partisipasi dalam fungsi dinamika kelompok kelas lanjut lebih tinggi 375 dibandingkan dengan kelas pemula yang hanya 371, Sehingga dapat dikatakan memiliki hubungan yang terbalik. Sedangkan tingkat partisipasi dalam tujuan dinamika kelompok kelas pemula dan kelas lanjut memiliki hubungan yang searah karena tingakt partisipasi dalam tujuan dinamika kelompok kelas pemula lebih tinggi dibandingkan tingkat partisipasi dalam tujuan dinamika kelompok kelas lanjut yang rendah, sehingga dapat dikatakan hubungan yang searah. Dan jumlah keseluruhan dari 36 indikator pertanyaan yang terdiri dari 15 pertanyaan bentuk - bentuk Partisipasi, 9 pertanyaan fungsi dinamika kelompok, 12 pertanyaan tujuan dinamika kelompok mendapatkan jumlah total skor keseluruhan yaitu 2989.

Di hitung berdasarkan jumlah skor ideal utnuk keseluruahan perntanyaan $=3600$, sedangkan jumlah skor terendah $=720$, dan berdasarkan data dihimpun dari sebanyak 36 indikator berupa instrument pernyataan yang diberikan kepada 20 responden yang tergabung dalam kelompok tani kelas pemula dan kelas lanjut, maka diperoleh total skor 2989. Secara presentase, angka indeks partisipasi kelompok tani terhadap dinamika kelompok tani di desa Ongkaw Dua sebagai berikut:

Partisipasi Kelompok Tani Terhadap Dinamika Jumlah skor hasil

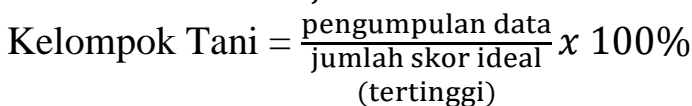

$$
\begin{aligned}
& =\frac{\mathbf{2 9 8 9}}{3600} \times 100 \% \\
& =83,02 \%
\end{aligned}
$$

Berdasarkan hasil analisis menggunakan skala likert, indeks partisipasi kelompok tani terhadap dinamika kelompok tani di Desa Ongkaw Dua berada pada titik $83,02 \%$ dan tergolong dalam kategori sangat tinggi. Dan dapat dilihat bahwa kelompok tani Di Desa Ongkaw Dua sangat berpartisipasi dalam fungsi dan tujuan dinamika kelompok.

\section{KESIMPULAN DAN SARAN}

\section{Kesimpulan}

Bentuk - bentuk partisipasi kelompok tani Di Desa Ongkaw Dua yang didalamnya ada partisipasi buah pikiran, partisipasi tenaga, partisipasi harta benda, partisipasi keterampilan, partisipasi sosial dari total skor tergolong sangat tinggi, juga Fungsi dinamika kelompok dan Tujuan dinamika kelompok mendapatkan interpretasi yang sangat tinggi. Partisipasi Kelompok Tani Terhadap Dinamika Kelommpok Tani di Desa Ongkaw Dua terbagi dalam dua tingkatan atau kelas yaitu kelas pemula dan kelas lanjut. Dalam penelitian ini dapat dilihat dari kelas pemula lebih tinggi tingkat partisipasinya dibandingkan dengan kelas lanjut. Namun dapat dilihat dari jumlah skor kelas pemula dan kelas lanjut, kelompok tani di Desa Ongkaw Dua sangat berpartisipasi dalam fungsi dan tujuan dinamika kelompok. 


\section{Saran}

Kepada kelompok tani kelas lanjut agar lebih meningkatkan partisipasi agar dapat mencapai keberhasilan dan tujan kelompok. Kepada kelompok tani kelas pemula agar mempertahankan atau lebih berpartisipasi lagi agar menjadi motivasi bagi kelompok tani lain. Kepada pemerintah desa agar selalu monopang kegiatan semua kelompok tani yang ada Di Desa Ongkaw Dua.

\section{DAFTAR PUSTAKA}

Anonim. 2007. Pedoman Pertumbuhan Dan Pengembangan Kelompok Tani Dan Gabungan Kelompok Tani, Jakarta.

$\begin{array}{lcr}\text { 2013. } & \text { Pedoman } & \text { Pembinaan } \\ \text { Kelompok Tani Dan } & \text { Gabungan } \\ \text { Kelompok Tani, Jakarta. } & \end{array}$

Damima, Y., 2001. Dinamika Kelompok Tani Padi Sawah Di Kecamatan Tondano Kabupaten Minahasa (Studi Kasus Terhadap Kelompok Tani di Desa Tataaran 1). Fakultas Pertanian Unsrat, Manado

Hermanto, 2007. Rancangan Kelembagaan Tani Dalam Implementasi Prima Tani Di Sumatera Selatan. Analisis Kebijakan Pertanian, Bogor.

Hernanto, F. 1995. Ilmu Usahatani. Penebar Swadaya, Jakarta.

Koampa, M. V., 2015. Partisipasi Kelompok Tani Dalam Kegiatan Penyuluhan Pertanian Di Desa Kanonang Lima, Kecamatan Kawangkoan Barat. UNSRAT, Manado.
Makawekes, N., 2016. Dinamika Kelompok Tani Cempaka Di Kelurahan Meras Kecamatan Bunaken Kota Manado. Fakultas Pertanian Universitas Sam Ratulangi. Manado.

Mamahit, Y., 2016. Modal Sosial Pada Kelompok Tani Esa Waya Di Desa Tumani Kabupaten Maesaan Kabupaten Minahasa Selatan. Fakultas Pertanian Universitas Samratulangi, Manado.

Mikkelsen, Britha., 2003. Metode Penelitian Partisipatoris dan Upaya - Upaya Pemberdayaan. (Penerjemah: Matheos Nalle). Yayasan Obor Indonesia, Jakarta.

Nurannisa, A., 2014. Dinamika Kelompok Masyarakat Perantau Kasus Anggota Kerukunan Keluarga Sulawesi Selatan (KKSS) Rumpun Siparappe di Kota Bau Bau, Makassar.

Nurmiayuni, F.W., 2014. Partisipasi Masyarakat Dalam Program Keaksaraan Fungsional Melalui Peningkatan Budaya. Yogyakarta.

Purwanto, S., 2011. Dinamika Kelompok Tani Hutan Dalam Pengelolaan Hutan Rakya. IPB, Bogor.

Santoso, S., 2004. Dinamika Kelompok. PT. Bumi Aksara, Jakarta.

Soekanto, S., dan Sulistyowati. 2013. Sosiologi Suatu Pengantar. PT. Raja Grafindo Persada, Jakarta.

Soetomo., 2006, Strategi-Strategi Pembangunan Masyarakat. Pustaka Pelajar, Yogyakarta. 